\title{
Effect of CPAP on Endothelial Function in Subjects With Obstructive Sleep Apnea: A Meta-Analysis
}

\author{
Huajun Xu MD, Yuyu Wang MD, Jian Guan MD PhD, Hongliang Yi MD PhD, and \\ Shankai Yin MD PhD
}

\author{
Introduction \\ Methods \\ Search Strategy and Selection Criteria \\ Data Collection \\ Quality Assessment \\ Statistical Analysis \\ Results \\ Search Results \\ Study Characteristics \\ Effect of CPAP on FMD or NMD \\ Subgroup Analysis \\ Sensitivity Analysis \\ Publication Bias \\ Discussion \\ Summary
}

\begin{abstract}
Obstructive sleep apnea (OSA) is related to endothelial dysfunction. CPAP is the first-line treatment for OSA. We conducted a meta-analysis to evaluate the effect of CPAP on endothelial function in subjects with OSA. The PubMed, Embase, and Cochrane Library databases were searched. The overall effects were measured by the weighted mean difference with a 95\% CI. Subgroup and meta-regression analyses were used to explore the sources of between-study heterogeneity. Eleven studies were eligible for the meta-analysis. A random-effects model revealed that CPAP significantly improved endothelial function as assessed by flow-mediated dilation (weighted mean difference of $2.92,95 \%$ CI $2.21-3.63, P<.001$ ), whereas there was no significant improvement in endothelial function in response to nitroglycerin-mediated dilation (weighted mean difference of $0.90,95 \% \mathrm{CI}-1.63$ to $3.43, P=.48$ ). Age, sex, CPAP compliance and duration, and sleep-related variables had no effect on reduction in arterial stiffness after CPAP. Sensitivity analyses indicated that the protective effect of CPAP on endothelial function was robust. CPAP significantly improved flow-mediated dilation in subjects with OSA. Long-term randomized controlled trials with larger sample sizes are needed to confirm the positive effect of CPAP on endothelial function in subjects with OSA. Key words: endothelial function; meta-analysis; continuous positive airway pressure; obstructive sleep apnea. [Respir Care 2015;60(5):749-755. () 2015 Daedalus Enterprises]
\end{abstract}

\section{Introduction}

Obstructive sleep apnea (OSA) is a clinical disorder characterized by repeated episodes of complete or partial

\footnotetext{
The authors are affiliated with the Department of Otolaryngology, Shanghai Jiao Tong University Affiliated Sixth People's Hospital, Shanghai, China.

Drs Xu and Wang are co-first authors
}

The authors have disclosed no conflicts of interest. upper-airway obstruction during sleep. ${ }^{1}$ The ensuing activation of oxidative stress and the resulting systemic inflammation are key factors in the pathogenesis of OSA-

\footnotetext{
Correspondence: Jian Guan MD PhD and Shankai Yin MD PhD, Department of Otolaryngology, Shanghai Jiao Tong University Affiliated Sixth People's Hospital, Otolaryngology Institute of Shanghai Jiao Tong University, 600 Yishan Road, Shanghai 200233, China. E-mail: guanjian0606@sina.com and yinshankai@china.com.
}

DOI: $10.4187 /$ respcare.03739 


\section{CPAP And Endothelial Function in SubJects With OSA}

related cardiovascular complications. ${ }^{2}$ Endothelial dysfunction is indicative of the early stage of atherosclerosis and is an independent predictor of cardiovascular morbidity and mortality. ${ }^{3,4}$ Endothelial dysfunction was shown to be positively associated with the risk of subsequent cardiovascular events in OSA. ${ }^{5}$ This relationship has been explored using ultrasound in pathophysiological studies and clinical trials, in which flow-mediated dilation (FMD) and nitroglycerin-mediated dilation (NMD) served as biomarkers of vascular function and as surrogates in predicting the risk of a cardiovascular event. ${ }^{6}$

CPAP is currently recommended as the primary treatment in the management of OSA. ${ }^{7}$ CPAP is effective in decreasing mean diastolic blood pressure and reducing the risk of serious cardiovascular outcomes. ${ }^{8}$ CPAP has a positive effect on reducing inflammation and oxidative stress and stimulating endothelial nitric oxide production. ${ }^{9}$ These factors play important roles in endothelial dysfunction in patients with OSA. Numerous studies have also explored the effects of CPAP on FMD as a surrogate vascular outcome. ${ }^{10-20}$ Although these studies demonstrated the favorable effect of CPAP on endothelial function, confounding factors such as obesity, insulin resistance, and metabolic syndrome, all of which influence endothelial function, must also be taken into account. In this review, we sought to retrieve all published studies on the effects of CPAP on FMD and NMD in subjects with OSA and to quantify the potential contribution of CPAP to improving endothelial function.

\section{Methods}

The Preferred Reporting Items for Systematic Reviews and Meta-Analyses (PRISMA) guidelines were strictly followed during the design, implementation, and reporting of this meta-analysis. ${ }^{21}$

\section{Search Strategy and Selection Criteria}

The PubMed, Embase, and Cochrane Library databases were searched using a combination of computerized and manual methods. The search terms were: (CPAP OR continuous positive airway pressure) combined with (obstructive sleep apnea hypopnea syndrome OR OSAHS OR obstructive sleep apnea syndrome OR OSAS OR obstructive sleep apnea OR OSA OR sleep apnea) and paired with (flow-mediated OR flow mediated OR FMD OR endothelial function OR endothelial dysfunction OR endotheliumdependent OR blood flow OR arterial stiffness OR vascular resistance). Two investigators (Drs $\mathrm{Xu}$ and Wang) independently performed the search. No restrictions, including language or study objectives, were applied.
The inclusion criteria were: (1) studies involved subjects with OSA; (2) CPAP treatment was used as the intervention, and its duration was at least 2 weeks, as we did not evaluate the acute effect of CPAP on endothelial function; (3) FMD or NMD was reported or estimated before and after CPAP intervention; and (4) subjects were adults ( $\geq 18 \mathrm{y}$ ). To avoid double-counting subjects, only the most recent article was included if data from duplicate publications or the same trials were identified. The exclusion criteria were: (1) reviews, abstracts, and non-human studies; (2) studies with other interventions that might influence endothelial function; (3) studies with subjects who were not treated with CPAP on a daily basis; and (4) unpublished studies for which we could not obtain data from the authors.

\section{Data Collection}

Data were extracted from the included studies by 2 reviewers (Drs Xu and Wang) and entered as standardized data into a data collection worksheet. The standardized data consisted of: (1) first author, year of publication, number of enrolled and compliant cases, adherence and duration of CPAP use, Epworth Sleepiness Score, percentage of males, and mean age of subjects; (2) apnea-hypopnea index and body mass index variables before and after CPAP; and (3) endothelial dysfunction-related variables, systolic blood pressure, diastolic blood pressure, FMD, and NMD before and after CPAP. Any inconsistencies were resolved by discussion, and the final data set was verified by all authors of this paper.

\section{Quality Assessment}

The methodological quality of all included studies was assessed according to the Newcastle-Ottawa Scale (http:// www.ohri.ca/programs/clinical_epidemiology/oxford.asp, Accessed March 11, 2015). The Newcastle-Ottawa Scale guideline was carried out as follows. A study was awarded a maximum of one star for each numbered item within the patient selection and outcome categories. A maximum of 4 stars were given for patient selection, 3 stars for outcome, and 2 stars for comparability. A higher number of stars indicated higher quality of the eligible study. One score represented one star.

\section{Statistical Analysis}

Review Manager 5.2 (Cochrane Collaboration, Oxford, United Kingdom) and Stata 10.0 (StataCorp, College Station, Texas) were used for statistical analyses. The pooled estimate of the weighted mean difference and 95\% CI for continuous data were calculated. The Mantel-Haenszel fixed-effects model or the DerSimonian-Laird random-ef- 


\section{CPAP and Endothelial Function in Subjects With OSA}

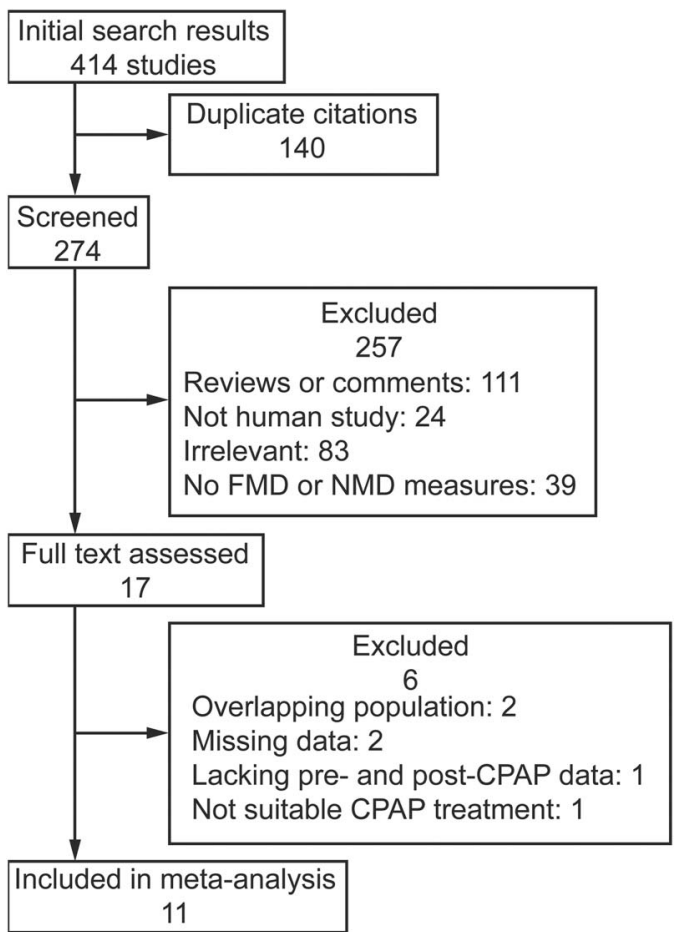

Fig. 1. Meta-analysis flow diagram. FMD = flow-mediated dilation; NMD = nitroglycerine-mediated dilation.

fects model was applied according to the non-heterogeneity or heterogeneity of the sample. ${ }^{22}$ Heterogeneity across the eligible studies was examined using the $Q$ test and $\mathrm{I}^{2}$ statistic $\left(P<.1\right.$ indicated significant heterogeneity). ${ }^{23}$ Potential publication bias was assessed by funnel plots and Egger's linear regression test. ${ }^{24}$ To explore the possible origin of heterogeneity across the included studies, both a meta-regression analysis according to a previous metaanalysis $^{25}$ and a subgroup analysis were performed.

\section{Results}

\section{Search Results}

A flow diagram showing our search procedure is presented in Figure 1. The initial search yielded 414 citations, of which 397 were excluded for various reasons. Thus, 17 candidate studies were potentially eligible. After carefully assessing the contents of these articles, we excluded 6 studies: 2 studies ${ }^{26,27}$ had an overlapping population, 2 studies $^{28,29}$ had missing data on FMD or NMD, one study ${ }^{30}$ lacked data before and after CPAP, and one study ${ }^{31}$ used CPAP for only $1 \mathrm{~d}$. Thus, 11 studies ${ }^{10-20}$ met all the inclusion criteria and were finally eligible for the meta-analysis. Five of the included studies ${ }^{10,11,15,16,20}$ evaluated both FMD and NMD, and the remaining 6 studies $^{12-14,17-19}$ evaluated
FMD only. Of the 199 subjects with OSA included in the meta-analysis, 199 were evaluated for FMD and 106 additionally for NMD. Controls were not included.

\section{Study Characteristics}

The basic characteristics of the eligible studies are shown in Table 1. The year of publication ranged from 2004 to 2013. Most subjects were males (67-100\%). The age range was 38-58.4 y of age. CPAP adherence ranged from 2.84 to $7.1 \mathrm{~h} / \mathrm{night}$, and the duration of CPAP use was 1-6 months. Table 1 provides further details on the Epworth Sleepiness Score, apnea-hypopnea index, body mass index, systolic blood pressure, diastolic blood pressure, measures of endothelial function (FMD and NMD) before and after CPAP, and quality assessment.

\section{Effect of CPAP on FMD or NMD}

FMD significantly improved after CPAP treatment (weighted mean difference of $2.92,95 \%$ CI 2.21-3.63, $P<.001$ ), whereas NMD did not (weighted mean difference of $0.90,95 \% \mathrm{CI}-1.63$ to $3.43, P=.48$ ). Significant heterogeneity was determined for both outcomes $\left(\mathrm{I}^{2}=76 \%\right.$, $P<.001 ; \mathrm{I}^{2}=63 \%, P=.03$ ) (Figs. 2 and 3, respectively). Meta-regression analyses performed to explore the origin of the heterogeneity (Table 2) showed no significant effects of the examined covariates: proportion of males; mean age; CPAP compliance; CPAP duration; and CPAP-related changes in body mass index, systolic blood pressure, diastolic blood pressure, and apnea-hypopnea index. This result suggested that changes in endothelial function were independent of changes in any of the aforementioned factors.

\section{Subgroup Analysis}

A subgroup analysis stratified by mean age, CPAP adherence, and CPAP duration was conducted. When stratified by mean age $(<50$ or $\geq 50 \mathrm{y})$, CPAP treatment significantly improved FMD in both younger (weighted mean difference of $3.23,95 \%$ CI 1.15-5.31, $P=.001$, $\mathrm{I}^{2}=80 \%$ ) and older (weighted mean difference of 2.59 , $95 \%$ CI $\left.1.87-3.31, P=.002, \mathrm{I}^{2}=74 \%\right)$ subjects with OSA. In those with good CPAP compliance ( $\geq 4 \mathrm{~h}$ daily), FMD improved significantly after CPAP treatment (weighted mean difference of 3.08, 95\% CI 1.39-4.77, $P<.001, \mathrm{I}^{2}=79 \%$ ). In studies examining CPAP use for $<3$ or $\geq 3$ months, significant improvements in NMD 


\section{CPAP and Endothelial Function in Subjects With OSA}

Table 1. Description of Characteristics of Included Studies

\begin{tabular}{|c|c|c|c|c|c|c|c|c|c|c|c|c|}
\hline Reference & $\begin{array}{l}\text { No. of } \\
\text { Enrolled } \\
\text { Cases }\end{array}$ & $\begin{array}{l}\text { No. of } \\
\text { Compliant } \\
\text { Cases }\end{array}$ & Age (y) & $\begin{array}{l}\text { Male } \\
(\%)\end{array}$ & \multicolumn{2}{|c|}{$\begin{array}{c}\text { CPAP } \\
\text { Adherence (h) }\end{array}$} & $\begin{array}{c}\text { CPAP } \\
\text { Duration (mo) }\end{array}$ & ESS Score & \multicolumn{2}{|c|}{$\begin{array}{l}\text { BMI Before } \\
\text { CPAP }\left(\mathrm{kg} / \mathrm{m}^{2}\right)\end{array}$} & \multicolumn{2}{|c|}{$\begin{array}{c}\text { BMI After } \\
\text { CPAP }\left(\mathrm{kg} / \mathrm{m}^{2}\right)\end{array}$} \\
\hline Kohler $^{10}$ & 64 & 31 & $58.4 \pm 7.2$ & 84.1 & \multicolumn{2}{|r|}{2.84} & 6 & $8.4 \pm 4.1$ & \multicolumn{2}{|c|}{$32.2 \pm 5.6$} & \multicolumn{2}{|c|}{$32.3 \pm 5.6$} \\
\hline Bakker $^{11}$ & 27 & 15 & 48 & 73 & \multicolumn{2}{|c|}{$7.1 \pm 2.3$} & 5.37 & - & \multicolumn{2}{|c|}{$33.8 \pm 4.9$} & \multicolumn{2}{|c|}{$34.1 \pm 5.5$} \\
\hline Del Ben ${ }^{12}$ & 91 & 10 & $56.6 \pm 9.8$ & 83.3 & \multicolumn{2}{|c|}{$\geq 4$} & 6 & - & \multicolumn{2}{|c|}{$35.3 \pm 5.4$} & \multicolumn{2}{|c|}{$36.0 \pm 6.0$} \\
\hline Panoutsopoulos ${ }^{1}$ & 38 & 14 & $54.3 \pm 10.8$ & - & \multicolumn{2}{|c|}{-} & 3 & - & \multicolumn{2}{|c|}{$31.3 \pm 2.0$} & \multicolumn{2}{|c|}{-} \\
\hline Chung ${ }^{14}$ & 52 & 25 & $51.4 \pm 11.5$ & 88 & \multicolumn{2}{|c|}{$4.6 \pm 1.4$} & 4.5 & - & \multicolumn{2}{|c|}{$27.7 \pm 3.7$} & \multicolumn{2}{|c|}{$27.7 \pm 3.8$} \\
\hline Butt $^{15}$ & 36 & 36 & $49 \pm 10$ & 72.2 & \multicolumn{2}{|c|}{$\geq 4$} & 6 & $13 \pm 5.0$ & \multicolumn{2}{|c|}{$34 \pm 8$} & \multicolumn{2}{|c|}{$34 \pm 8$} \\
\hline Nguyen ${ }^{16}$ & 35 & 10 & $52.9 \pm 11.6$ & 80 & \multicolumn{2}{|c|}{$5.1 \pm 1.9$} & 3 & - & \multicolumn{2}{|c|}{$30.1 \pm 4.7$} & \multicolumn{2}{|c|}{-} \\
\hline Bayram $^{17}$ & 29 & 20 & 44.3 & 100 & \multicolumn{2}{|c|}{$5.9 \pm 0.1$} & 6 & - & \multicolumn{2}{|c|}{30.5} & \multicolumn{2}{|c|}{ - } \\
\hline Jelic $^{18}$ & 30 & 14 & $38 \pm 11$ & 67 & \multicolumn{2}{|c|}{$6.1 \pm 1.5$} & 1 & $15 \pm 7.7$ & \multicolumn{2}{|l|}{$34 \pm 8$} & \multicolumn{2}{|c|}{-} \\
\hline Ohike $^{19}$ & 10 & 10 & $53.3 \pm 10.5$ & 100 & \multicolumn{2}{|c|}{-} & 1 & - & $29.1 \pm 4$ & & $28.0=$ & 4.7 \\
\hline $\mathrm{Ip}^{20}$ & 28 & 14 & $44.4 \pm 6.9$ & 100 & & 4.2 & 2 & - & $29.6 \pm 5$ & & - & \\
\hline $\begin{array}{c}\text { SBP Before } \\
\text { CPAP } \\
(\mathrm{mm} \mathrm{Hg})\end{array}$ & $\begin{array}{l}\text { SBP After } \\
\text { CPAP } \\
(\mathrm{mm} \mathrm{Hg})\end{array}$ & $\begin{array}{c}\text { DBP } \\
\text { Before } \\
\text { CPAP } \\
(\mathrm{mm} \mathrm{Hg})\end{array}$ & $\begin{array}{l}\text { DBP After } \\
\text { CPAP } \\
(\mathrm{mm} \mathrm{Hg})\end{array}$ & $\begin{array}{l}\mathrm{AHI} B \\
\mathrm{CP}\end{array}$ & $\begin{array}{l}\text { efore } \\
\text { AP }\end{array}$ & $\begin{array}{l}\text { AHI } \\
\text { After } \\
\text { CPAP }\end{array}$ & $\begin{array}{c}\text { FMD } \\
\text { Before } \\
\text { CPAP }(\%)\end{array}$ & $\begin{array}{l}\text { FMD After } \\
\text { CPAP }(\%)\end{array}$ & $\begin{array}{c}\text { NMD } \\
\text { Before } \\
\text { CPAP }(\%)\end{array}$ & & $\begin{array}{l}\text { ID After } \\
\text { AP }(\%)\end{array}$ & $\begin{array}{l}\text { NOS } \\
\text { Score }\end{array}$ \\
\hline $129.7 \pm 11.6$ & $131.1 \pm 13.4$ & - & - & - & & - & $3.4 \pm 3.4$ & $4.4 \pm 3.0$ & $14.5 \pm 5.1$ & 13.2 & $2 \pm 4.9$ & 9 \\
\hline $118 \pm 16.3$ & $122 \pm 10.4$ & $72 \pm 17.0$ & $75 \pm 11.1$ & $36.5 \pm$ & 38.9 & $5.3 \pm 6.9$ & $5.5 \pm 6.1$ & $2.8 \pm 3.3$ & $17.0 \pm 7.9$ & 13.0 & $0 \pm 10.3$ & 8 \\
\hline- & - & - & - & $43.4 \pm$ & 12.6 & $7 \pm 5$ & $3.6 \pm 4.2$ & $7.0 \pm 4.7$ & - & & - & 7 \\
\hline $124.4 \pm 4.8$ & - & $77.0 \pm 5.9$ & - & $25.4 \pm$ & 15.1 & - & $6.3 \pm 0.5$ & $9.2 \pm 0.6$ & - & & - & 5 \\
\hline $129.0 \pm 9.5$ & $129.4 \pm 14.9$ & $84.8 \pm 10.3$ & $82.1 \pm 9.7$ & $64.9 \pm$ & 20.0 & $4.1 \pm 2.0$ & $5.5 \pm 2.5$ & $6.6 \pm 2.5$ & - & & - & 5 \\
\hline $141 \pm 17$ & $133 \pm 12$ & $83 \pm 12$ & $79 \pm 8$ & $36 \pm$ & 22.2 & - & $7.0 \pm 3.0$ & $13.0 \pm 6.0$ & $12 \pm 4$ & & $6 \pm 7$ & 8 \\
\hline $121.0 \pm 11.6$ & $126.0 \pm 15.8$ & $75.2 \pm 11.1$ & $83.9 \pm 10.6$ & $38.8 \pm$ & 21.4 & $2.2 \pm 1.5$ & $2.5 \pm 5.7$ & $9.0 \pm 6.5$ & $7.0 \pm 5.0$ & & $0 \pm 7.0$ & 9 \\
\hline $127.4 \pm 11.4$ & - & $79.3 \pm 7.0$ & - & 59 & & - & $7.4 \pm 2.1$ & $10.5 \pm 1.7$ & - & & - & 8 \\
\hline $120 \pm 17$ & - & $74 \pm 8$ & - & 25 & & - & $3.7 \pm 12.9$ & $7.2 \pm 15.9$ & - & & - & 9 \\
\hline $131 \pm 15.2$ & $133 \pm 8.8$ & $79 \pm 9.3$ & $81 \pm 6.5$ & $33 \pm$ & 14.7 & - & $3.3 \pm 0.3$ & $6.6 \pm 0.3$ & - & & - & 5 \\
\hline $122.1 \pm 11.5$ & - & $77.9 \pm 11.1$ & - & $47.7 \pm$ & 15.3 & $1.7 \pm 1.8$ & $5.1 \pm 1.4$ & $9.6 \pm 1.6$ & $15.0 \pm 3.7$ & 16.5 & $5 \pm 3.6$ & 9 \\
\hline
\end{tabular}

If an SE was provided, we recalculated it to SD according to the Cochrane Handbook for Systematic Reviews of Interventions. ${ }^{23}$ A dash indicates that the data were not provided by the study. ESS $=$ Epworth Sleepiness Scale

$\mathrm{BMI}=$ body mass index

$\mathrm{SBP}=$ systolic blood pressure

$\mathrm{DBP}=$ diastolic blood pressure

$\mathrm{AHI}=$ apnea-hypopnea index

FMD $=$ flow-mediated dilation

NMD $=$ nitroglycerine-mediated dilatation

NOS $=$ Newcastle-Ottawa Scale

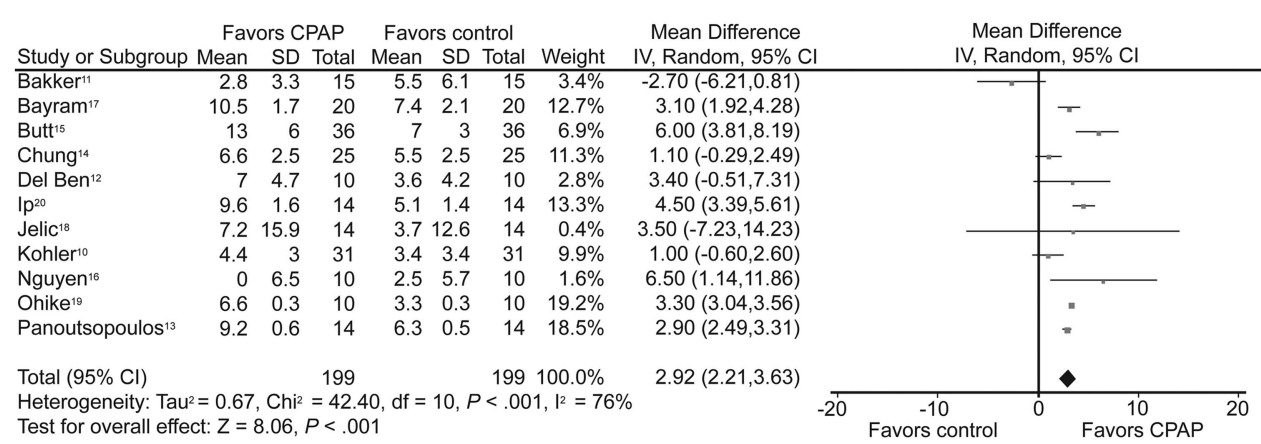

Fig. 2. Meta-analysis of the effect of CPAP on flow-mediated dilation in subjects with obstructive sleep apnea. IV $=$ inverse variance (method used to pool continuous data in a meta-analysis).

occurred in both groups (weighted mean difference of 3.73, 95\% CI 2.75-4.71, $P<.001, \mathrm{I}^{2}=53 \%$; weighted mean difference of $2.49,95 \%$ CI $1.28-3.69, P<.001, \mathrm{I}^{2}=77 \%$ ).
Thus, according to the subgroup analysis, age, CPAP adherence, and CPAP duration did not account for the heterogeneity across the included studies. 


\section{CPAP and Endothelial Function in Subjects With OSA}

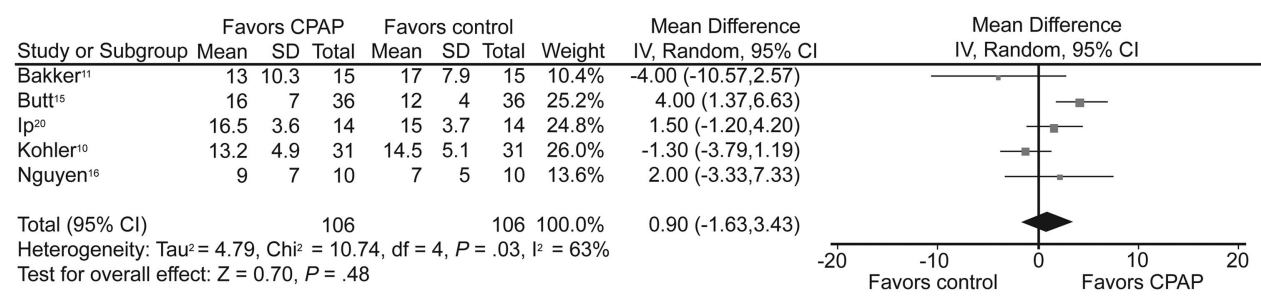

Fig. 3. Meta-analysis of the effect of CPAP on nitroglycerine-mediated dilatation in subjects with obstructive sleep apnea. IV $=$ inverse variance (method used to pool continuous data in a meta-analysis).

Table 2. Results of Meta-Regression Analysis Examining the Effect of Potential Cofounders on the Effect of CPAP on FMD

\begin{tabular}{lrcc}
\hline \hline \multirow{2}{*}{ Variable } & \multicolumn{2}{c}{$\begin{array}{c}\text { Endothelial Function Assessed by } \\
\text { Brachial Artery FMD }\end{array}$} \\
\cline { 2 - 4 } & No. of Trials & Exp(B) & $P$ \\
\hline Mean age & 11 & -0.50 & .63 \\
Proportion of males & 10 & 2.31 & .050 \\
CPAP adherence & 7 & 0.44 & .68 \\
CPAP duration & 11 & -1.61 & .14 \\
BMI before CPAP & 11 & -1.21 & .26 \\
BMI after CPAP & 6 & -1.10 & .33 \\
SBP before CPAP & 10 & 0.03 & .97 \\
SBP after CPAP & 6 & 0.60 & .58 \\
DBP before CPAP & 9 & 0.07 & .94 \\
DBP after CPAP & 5 & 0.05 & .96 \\
AHI before CPAP & 10 & 0.08 & .94 \\
AHI after CPAP & 5 & -0.71 & .53 \\
& & & \\
Exp(B) is the value of the risk ratio of continuous variables. & & \\
FMD = flow-mediated dilation & & & \\
BMI = body mass index & & & \\
SBP $=$ systolic blood pressure & & & \\
DBP = diastolic blood pressure & & & \\
AHI = apnea/hypopnea index & & & \\
\hline
\end{tabular}

\section{Sensitivity Analysis}

A sensitivity analysis was used to examine the influence of each included study on the pooled result. This analysis was performed by sequentially omitting individual studies. For FMD, the pooled weighted mean difference ranged from 2.68 (95\% CI $1.94-3.43$ ) to 3.16 (95\% CI $2.46-$ 3.86). For NMD, the pooled weighted mean difference ranged from -0.08 (95\% CI -2.23 to 2.07$)$ to $1.82(95 \% \mathrm{CI}$ -0.7 to 4.39 ). The analysis did not change the statistical significance of the pooled estimate.

\section{Publication Bias}

Funnel plots showed no significant asymmetry in the meta-analyses of FMD and NMD (data not shown). Egger's linear regression test also indicated an absence of publication bias for FMD $(P=.60)$ and NMD $(P=.55)$.

\section{Discussion}

Using a systematic review and meta-analysis, we evaluated the published evidence regarding the effect of CPAP on endothelial function as measured by FMD and NMD. The pooled data showed that CPAP therapy substantially enhanced FMD (weighted mean difference of $2.92,95 \%$ CI 2.21-3.63, $P<.001$ ) and had a positive effect on endothelium-dependent vasodilation. However, CPAP treatment had no significant effect on NMD (weighted mean difference of $0.90,95 \% \mathrm{CI}-1.63$ to $3.43, P=.48$ ).

OSA is associated with numerous cardiovascular conditions. ${ }^{3,4,32}$ Importantly, endothelial dysfunction (assessed by brachial artery FMD and NMD) is an independent risk factor for development of conventional cardiovascular disease. ${ }^{6,33}$ Circulating endothelial cell and endothelial progenitor cell values, which serve as surrogate markers of endothelial damage and repair, are elevated in OSA and its complications, including conventional cardiovascular disease. ${ }^{34}$ The mechanisms of OSA-induced endothelial dysfunction are not completely understood, but several pathways related to intermittent hypoxia and sleep deprivation are thought to be involved. Intermittent hypoxia induces the formation of reactive oxygen species, which damage endothelial cells by promoting superoxide production, thus suppressing the phosphorylation of endothelial nitric oxide synthase, which reduces the activity of this enzyme ${ }^{35}$ and thereby endothelial nitric oxide bioavailability. ${ }^{36}$ Additionally, intermittent hypoxia activates pro-inflammatory pathways, leading to low-grade systemic inflammation and thus endothelial dysfunction. ${ }^{37}$ Sleep deprivation also induces a reduction in endothelium-dependent vasodilation that is associated with alterations in nitric oxide synthase and cyclooxygenase pathways. ${ }^{38}$ The beneficial effect of CPAP on endothelial dysfunction in subjects with OSA partially stems from reductions in oxidative and inflammatory activities, as well as improvements in both endothelial repair capacity and nitric oxide bioavailability. ${ }^{10-20}$

The subgroup analysis showed that with respect to improved FMD, a longer duration of CPAP was no better than a shorter duration $(2.49 \%$ vs $3.73 \%)$. After 1 week, CPAP significantly changed the FMD of subjects with OSA compared with the baseline level, from $3.3 \pm 0.3 \%$ 


\section{CPAP and Endothelial Function in Subjects With OSA}

to $5.8 \pm 0.4 \% .{ }^{19}$ According to one study, a beneficial effect was achieved after one night of CPAP. ${ }^{31}$ However, in subjects with OSA in whom FMD was measured 1 week later, FMD was significantly lower than immediately after the end of treatment $(5.0 \pm 0.7 \%$ vs $8.9 \pm 1.9 \%)$ and was similar to the baseline level. ${ }^{20}$ Thus, CPAP might have an acute but reversible effect on endothelial function. Because the duration of CPAP in the included studies was short (1-6 months), the effect of a longer duration ( $\geq 12$ months) of CPAP on FMD remains to be explored. CPAP compliance is another important issue. A beneficial effect of CPAP was observed even in OSA subjects who used CPAP for $<4 \mathrm{~h} /$ night, and a dose-dependent correlation was found. ${ }^{10}$ However, in another study, there were no changes in FMD with CPAP use of $<4 \mathrm{~h} /$ night or in subjects who declined CPAP $(5.0 \pm 2.38 \%$ vs $4.30 \pm 2.60 \%) .{ }^{18}$ In 7 of the studies included in our metaanalysis, mean CPAP use was clearly stated and was comparable to that reported by Vlachantoni et al, ${ }^{25}$ who found that treatment duration did not alter the positive effect of CPAP on arterial stiffness. In agreement with that study, we found that changes in endothelial function were independent of changes in CPAP compliance.

Several characteristics of patients with OSA undergoing CPAP and the relationship of treatment to endothelial function merit consideration. The presence or absence of conventional cardiovascular disease in patients with OSA could impact endothelial dysfunction. In one study that was excluded from our meta-analysis, endothelial function was assessed in subjects with OSA but without conventional cardiovascular disease by measuring vascular reactivity after the administration of salbutamol and glyceryl trinitrate; in those subjects, CPAP had no effect on vascular function. ${ }^{39}$ In our meta-analysis, most of the included studies did not clearly state whether the subjects had conventional cardiovascular disease, which prevented us from determining whether CPAP treatment had a greater impact on subjects with OSA alone or on subjects with both OSA and conventional cardiovascular disease. Excessive daytime sleepiness is another factor that may impact cardiovascular responsiveness in patients treated with CPAP. One study showed that residual excessive daytime sleepiness in subjects with OSA adequately treated with CPAP was not associated with increased concentrations of inflammatory markers or endothelial dysfunction. ${ }^{40}$ The authors therefore suggested that residual excessive daytime sleepiness in subjects with adequately treated OSA may not be a risk factor for conventional cardiovascular disease. However, the sample size in that study was small, so the relationship remains to be explored in a larger series. Arterial stiffness, which is an early sign of atherosclerosis, is caused by oxidative stress and increased inflammation. In the meta-analysis by Vlachantoni et al, ${ }^{25}$ who aimed to identify a potential relationship between CPAP treatment for OSA and arterial stiffness, all indices of arterial stiffness significantly improved after CPAP. Thus, the improvements in endothelial function and arterial stiffness achieved with CPAP may contribute to a decrease in OSAinduced cardiovascular implications.

To the best of our knowledge, this is the first metaanalysis to investigate the effects of CPAP on endothelial function in subjects with OSA. The statistical analysis supports the positive effect of this treatment. Nonetheless, the limitations of this study should be noted. First, most of the included studies were observational rather than randomized controlled trials. Thus, in comparisons of pretreatment and post-treatment data, potential confounding factors may have affected the findings. Second, the subjects with OSA enrolled in the included studies were older and overweight, and the results may not be generalizable to different populations. Third, the duration of CPAP in the included studies was relatively short; the long-term effects of CPAP on endothelial function remain to be determined. Fourth, there was some evidence of heterogeneity among the studies, although we were unable to identify its source by either meta-regression or subgroup analysis. Nonetheless, it should also be noted that although the total sample size in this meta-analysis was relatively small, a power analysis showed that it had sufficient power to detect a positive effect of CPAP on FMD or NMD.

\section{Summary}

In conclusion, our meta-analysis provides further evidence that CPAP can improve endothelial function in subjects with OSA. Long-term randomized controlled trials with larger sample sizes and longer CPAP duration are needed to confirm our findings.

\section{REFERENCES}

1. Strollo PJ Jr, Rogers RM. Obstructive sleep apnea. N Engl J Med 1996;334(2):99-104.

2. Can M, Açikgöz S, Mungan G, Bayraktaroğlu T, Koçak E, Güven B, Demirtas S. Serum cardiovascular risk factors in obstructive sleep apnea. Chest 2006;129(2):233-237.

3. Ross R. The pathogenesis of atherosclerosis: a perspective for the 1900s. Nature 1993;362(6423):801-809.

4. Libby P, Theroux P. Pathophysiology of coronary artery disease. Circulation 2005;111(25):3481-3488.

5. Sánchez-de-la-Torre M, Campos-Rodriguez F, Barbé F. Obstructive sleep apnoea and cardiovascular disease. Lancet Respir Med 2013; 1(1):61-72.

6. Brevetti G, Silvestro A, Schiano V, Chiariello M. Endothelial dysfunction and cardiovascular risk prediction in peripheral arterial disease: additive value of flow-mediated dilation to ankle-brachial pressure index. Circulation 2003;108(17):2093-2098.

7. Berg S. Obstructive sleep apnoea syndrome: current status. Clin Respir J 2008;2(4):197-201.

8. Campos-Rodriguez F, Martinez-Garcia MA, Reyes-Nuñez N, Caballero-Martinez I, Catalan-Serra P, Almeida-Gonzalez CV. Role of sleep apnea and CPAP therapy in the incidence of stroke or coronary 


\section{CPAP and Endothelial Function in Subjects With OSA}

heart disease in women. Am J Respir Crit Care Med 2014;189(12): 1544-1550.

9. Hoyos CM, Melehan KL, Liu PY, Grunstein RR, Phillips CL. Does obstructive sleep apnea cause endothelial dysfunction? A critical review of the literature. Sleep Med Rev 2015;20:15-26

10. Kohler M, Craig S, Pepperell JC, Nicoll D, Bratton DJ, Nunn AJ, et al. CPAP improves endothelial function in patients with minimally symptomatic OSA: results from a subset study of the MOSAIC trial. Chest 2013;144(3):896-902.

11. Bakker JP, Balachandran JS, Tecilazich F, Deyoung PN, Smales E, Veves A, Malhotra A. Pilot study of the effects of bariatric surgery and continuous positive airway pressure treatment on vascular function in obese subjects with obstructive sleep apnoea. Intern Med J 2013;43(9):993-998.

12. Del Ben M, Fabiani M, Loffredo L, Polimeni L, Carnevale R, Baratta $\mathrm{F}$, et al. Oxidative stress mediated arterial dysfunction in patients with obstructive sleep apnoea and the effect of continuous positive airway pressure treatment. BMC Pulm Med 2012;12:36.

13. Panoutsopoulos A, Kallianos A, Kostopoulos K, Seretis C, Koufogiorga E, Protogerou A, et al. Effect of CPAP treatment on endothelial function and plasma CRP levels in patients with sleep apnea. Med Sci Monit 2012;18(12):CR747-CR751.

14. Chung S, Yoon IY, Lee CH, Kim JW. The effects of nasal continuous positive airway pressure on vascular functions and serum cardiovascular risk factors in obstructive sleep apnea syndrome. Sleep Breath 2011;15(1):71-76.

15. Butt M, Khair OA, Dwivedi G, Shantsila A, Shantsila E, Lip GY. Myocardial perfusion by myocardial contrast echocardiography and endothelial dysfunction in obstructive sleep apnea. Hypertension 2011;58(3):417-424.

16. Nguyen PK, Katikireddy CK, McConnell MV, Kushida C, Yang PC. Nasal continuous positive airway pressure improves myocardial perfusion reserve and endothelial-dependent vasodilation in patients with obstructive sleep apnea. J Cardiovasc Magn Reson 2010;12:50.

17. Bayram NA, Ciftci B, Keles T, Durmaz T, Turhan S, Bozkurt E, Peker Y. Endothelial function in normotensive men with obstructive sleep apnea before and 6 months after CPAP treatment. Sleep 2009; 32(10): 1257-1263.

18. Jelic S, Padeletti M, Kawut SM, Higgins C, Canfield SM, Onat D, et al. Inflammation, oxidative stress, and repair capacity of the vascular endothelium in obstructive sleep apnea. Circulation 2008; 117(17):2270-2278

19. Ohike Y, Kozaki K, Iijima K, Eto M, Kojima T, Ohga E, et al. Amelioration of vascular endothelial dysfunction in obstructive sleep apnea syndrome by nasal continuous positive airway pressure-possible involvement of nitric oxide and asymmetric NG, NG-dimethylarginine. Circ J 2005;69(2):221-226.

20. Ip MS, Tse HF, Lam B, Tsang KW, Lam WK. Endothelial function in obstructive sleep apnea and response to treatment. Am J Respir Crit Care Med 2004;169(3):348-353.

21. Liberati A, Altman DG, Tetzlaff J, Mulrow C, Gøtzsche PC, Ioannidis JP, et al. The PRISMA statement for reporting systematic reviews and meta-analyses of studies that evaluate health care interventions: explanation and elaboration. BMJ 2009;339:b2700.

22. DerSimonian R, Kacker R. Random-effects model for meta-analysis of clinical trials: an update. Contemp Clin Trials 2007;28(2):105114.

23. Higgins JP, Green S (editors). Cochrane handbook for systematic reviews of interventions, version 5.1.0 [updated March 2011]. http:// www.cochrane-handbook.org.
24. Egger M, Davey Smith G, Schneider M, Minder C. Bias in metaanalysis detected by a simple, graphical test. BMJ 1997;315(7109): 629-634.

25. Vlachantoni IT, Dikaiakou E, Antonopoulos CN, Stefanadis C, Daskalopoulou SS, Petridou ET. Effects of continuous positive airway pressure (CPAP) treatment for obstructive sleep apnea in arterial stiffness: a meta-analysis. Sleep Med Rev 2013;17(1):19-28.

26. Kohler M, Pepperell JC, Casadei B, Craig S, Crosthwaite N, Stradling JR, Davies RJ. CPAP and measures of cardiovascular risk in males with OSAS. Eur Respir J 2008;32(6):1488-1496.

27. Jelic S, Lederer DJ, Adams T, Padeletti M, Colombo PC, Factor P, Le Jemtel TH. Endothelial repair capacity and apoptosis are inversely related in obstructive sleep apnea. Vasc Health Risk Manag 2009;5:909-920.

28. Kohler M, Stoewhas AC, Ayers L, Senn O, Bloch KE, Russi EW, Stradling JR. Effects of continuous positive airway pressure therapy withdrawal in patients with obstructive sleep apnea: a randomized controlled trial. Am J Respir Crit Care Med 2011;184(10):11921199

29. Comondore VR, Cheema R, Fox J, Butt A, Mancini GBJ, Fleetham JA, et al. The impact of CPAP on cardiovascular biomarkers in minimally symptomatic patients with obstructive sleep apnea: a pilot feasibility randomized crossover trial. Lung 2009;187(1):17-22.

30. Ciccone MM, Favale S, Scicchitano P, Mangini F, Mitacchione G, Gadaleta F, et al. Reversibility of the endothelial dysfunction after CPAP therapy in OSAS patients. Int J Cardiol 2012;158(3):383-386.

31. Tulmaç M, Tireli E, Ebinç H, Şimşek V, Doğru MT, Yıldırım N, et al. Effect of overnight nasal continuous positive airway pressure treatment on the endothelial function in patients with obstructive sleep apnea. Anadolu Kardiyol Derg 2012;12(7):560-565.

32. Xu H, Yi H, Guan J, Yin S. Effect of continuous positive airway pressure on lipid profile in patients with obstructive sleep apnea syndrome: a meta-analysis of randomized controlled trials. Atherosclerosis 2014;234(2):446-453.

33. Yeboah J, Folsom AR, Burke GL, Johnson C, Polak JF, Post W, et al. Predictive value of brachial flow-mediated dilation for incident cardiovascular events in a population-based study: the Multi-Ethnic Study of Atherosclerosis. Circulation 2009;120(6):502-509.

34. Priou P, Gagnadoux F, Tesse A, Mastronardi ML, Agouni A, Meslier $\mathrm{N}$, et al. Endothelial dysfunction and circulating microparticles from patients with obstructive sleep apnea. Am J Pathol 2010;177(2):974983.

35. Tanaka T, Nakamura H, Yodoi J, Bloom ET. Redox regulation of the signaling pathways leading to eNOS phosphorylation. Free Radic Biol Med 2005;38(9):1231-1242.

36. Xia Y, Roman LJ, Masters BS, Zweier JL. Inducible nitric-oxide synthase generates superoxide from the reductase domain. J Biol Chem 1998;273(35):22635-22639.

37. Lavie L. Oxidative stress inflammation and endothelial dysfunction in obstructive sleep apnea. Front Biosci 2012;4:1391-1403.

38. Sauvet F, Florence G, Van Beers P, Drogou C, Lagrume C, Chaumes $\mathrm{C}$, et al. Total sleep deprivation alters endothelial function in rats: a nonsympathetic mechanism. Sleep 2014;37(3):465-473.

39. Jones A, Vennelle M, Connell M, McKillop G, Newby DE, Douglas NJ, Riha RL. The effect of continuous positive airway pressure therapy on arterial stiffness and endothelial function in obstructive sleep apnea: a randomized controlled trial in patients without cardiovascular disease. Sleep Med 2013;14(12):1260-1265.

40. El-Solh AA, Akinnusi ME, Moitheennazima B, Ayyar L, Relia S. Endothelial function in patients with post-CPAP residual sleepiness. J Clin Sleep Med 2010;6(3):251-255. 